Iraqi Journal of Industrial Research (IJOIR)

Journal homepage: http://ijoir.gov.iq

\title{
Evaluation of the Effect of Blades Number on the Performance of Pico Wind Turbines
}

\author{
${ }^{1}$ Yasir A. Abood*, ${ }^{1}$ Tariq A. Ismail, ${ }^{1}$ Omar A. Abdulrazzaq, ${ }^{1}$ Haider S. Hussein \\ ${ }^{1}$ Renewable Energy and Environment Research Center/ Corporation of Research and Industrial Development/ \\ Ministry of Industry and Minerals - Iraq
}

\section{Article information}

Article history:

Received: April, 01, 2021

Accepted: April, 05, 2021

Available online: June, 14, 2021

\section{Keywords:}

Pico wind turbine,

Blades number,

Wind power,

Power coefficient

*Corresponding Author:

Yasir A. Abood

yaabood@gmail.coms

DOI:

https://doi.org/10.53523/ijoirVol8I1ID20

\begin{abstract}
In this paper, the influence of blades number on the performance of pico wind turbine was investigated by using a small-motorized axial DC fan with a rated power of $4 \mathrm{~W}$. Fixed streaming air blower was used as a source of wind. Varying in wind speed was accomplished by changing the distance from the blower. A resistor equals to the turbine internal resistance was utilized as a load to collect the electrical power across the load at various wind speeds and for fans of different blades (1, 2, and 5). Values of the cut-in and cut-out speeds were extracted from the power plot. Rated power was recorded, as well. The results have shown that the rated power generated by turbine has decreased due to the reduction of blades number (i.e., reduction in solidity) from $2.6 \mathrm{~W}$ for a 5 -bladed turbine to $0.665 \mathrm{~W}$ for a 2 -bladed turbine and to $0.13 \mathrm{~W}$ for a 1 -bladed turbine. Moreover, the cut-in speed (initial electrical generating speed) has increased from $4.9 \mathrm{~m} / \mathrm{s}$ for 5 -bladed to $8 \mathrm{~m} / \mathrm{s}$ for 2-bladed, then to $19.15 \mathrm{~m} / \mathrm{s}$ for 1-bladed. These results are explained by the balancing problems during rotation (polar asymmetrical rotor), and it is seen that the reduction of blades has made a sharp reduction in power coefficient.
\end{abstract}

\section{Introduction}

The necessity of using renewable resources becomes more and more important because of the increase in the energy demand and due to the environmental challenges. As a worldwide opinion, the use of fossil resources has a great impact on the phenomenon (global warming). The experts of the climate groups [1] think that keeping the emission of gasses that warm our planet under certain levels should be paired with the reduction of the dependency on carbon in producing power by $80 \%$ by the year 2050 [2]. The technology of renewable energy (namely, the solar and wind energy) has grown significantly during the last two decades as shown in Figure (1) [2]. 


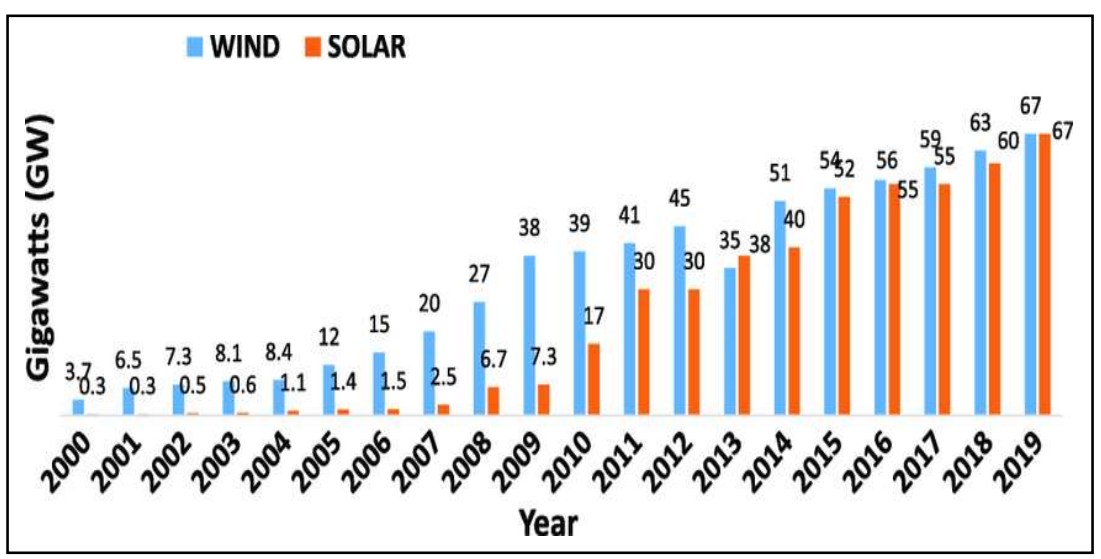

Figure (1). Global cumulative installation 2000-2019.

On the global level of installing wind turbines, if we take the official data of year 2009 alone [3-6], the world power capacity has increased by nearly $40 \mathrm{GW}$, reaching a total of $158 \mathrm{GW}$ as shown in Figure (2).

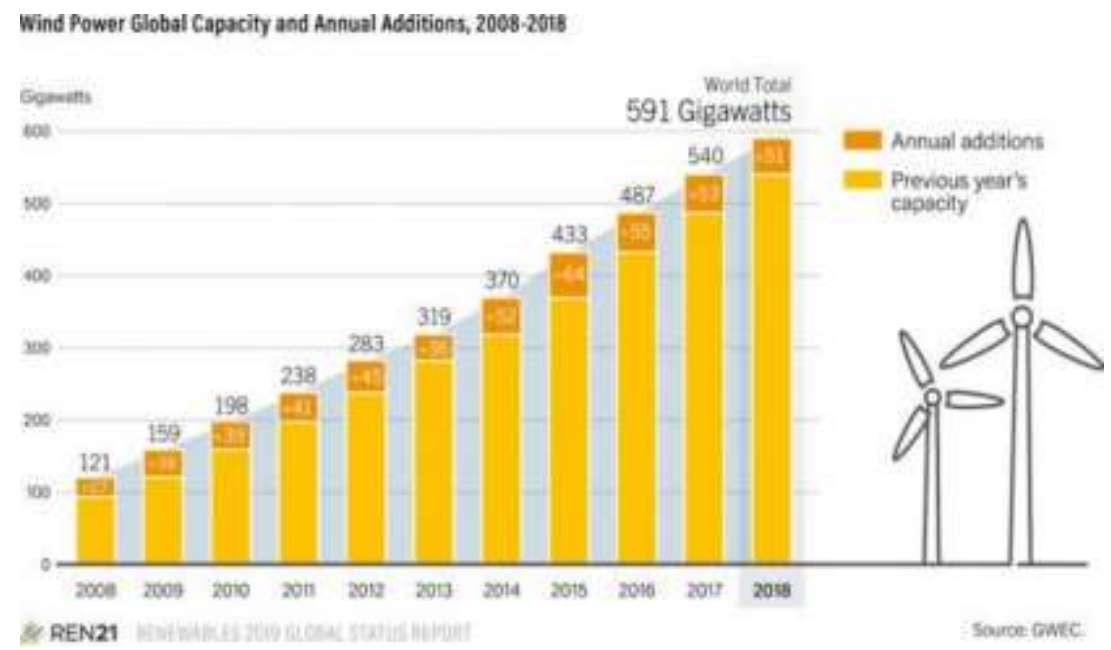

Figure (2). Worldwide evolution in wind power capacity.

Today, the most practical method to produce energy (electrical) is through wind turbines. The wind turbine is an application device that converts the wind kinetic energy into electrical energy. The scientific expression has been borrowed from hydroelectric technology (also called: rotary propeller). The adequate technical description for these kinds of machines is (aerofoil-powered generator) [3]. Basically, there are two types of wind turbines according to their axis of rotation to the ground as shown in Figure (3), which are:

1. Horizontal axis wind turbines (HAWTs).

2. Vertical axis wind turbines (VAWTs). 


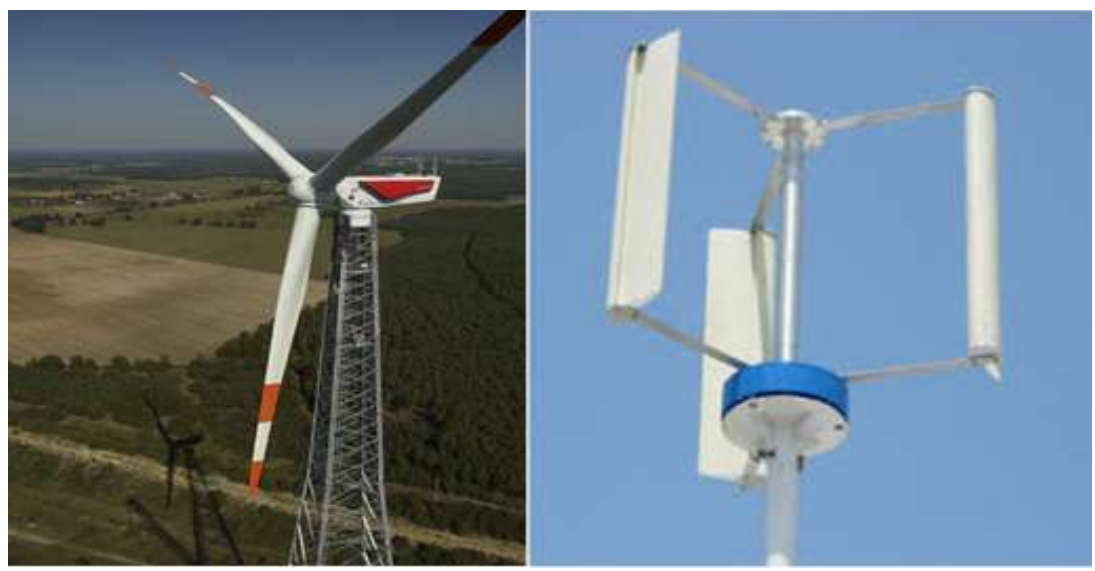

Figure (3). Horizontal (left), and vertical (right) wind turbines.

Each type has advantages and disadvantages. HAWTs are more common and widespread due to their high coefficient of performance and mechanical durability. Moreover, wind turbines can be divided according to their capacities to large wind turbines (LWT) and small wind turbines (SWT) as shown in Figure (4) [3, 4].
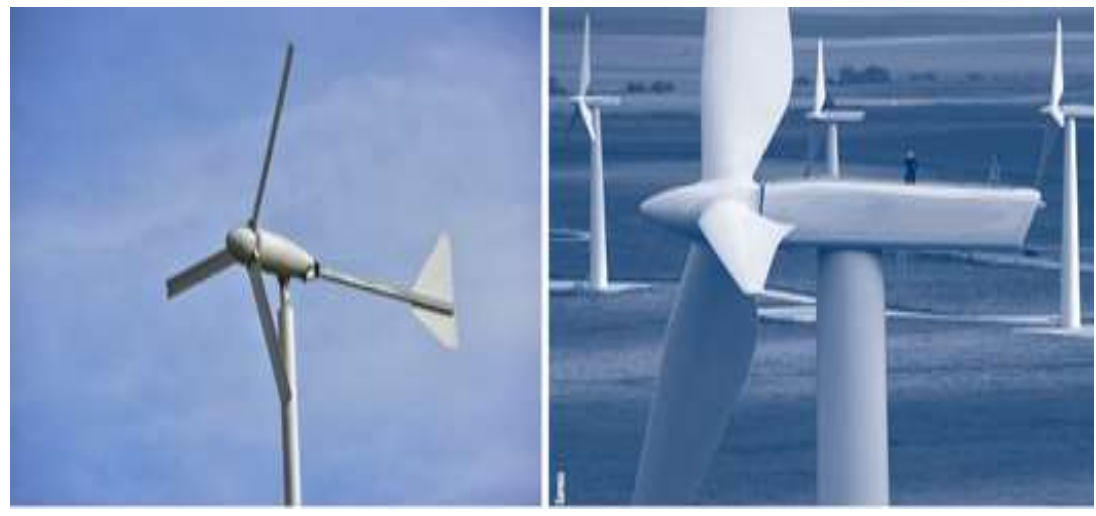

Figure (4). Small (left), and large (right) wind turbines.

This research will focus on the study of the small wind turbines. There are different ways to classify the ESWTs, and this classification varies from country to country. According to the specification of IEC 61400-2 Ed.2, the limit $100 \mathrm{~kW}$ makes the threshold between large and small wind turbines. This specification, categorizes the small wind turbines according to swept area (the imaginary circle area made by rotating blades) and capacity or rated power as shown in Table (1):

Table (1). SWT Classifications (IEC 61400-2) [3].

\begin{tabular}{|c|c|c|}
\hline Category & Rated Power & Rotor Swept Area \\
\hline Pico wind & $\mathrm{P}_{\text {rated }}<1 \mathrm{KW}$ & $\mathrm{A}<4.9 \mathrm{~m}^{2}$ \\
\hline Micro wind & $1 \mathrm{~kW}<\mathrm{P}_{\text {rated }}<7 \mathrm{~kW}$ & $\mathrm{~A}<40 \mathrm{~m}^{2}$ \\
\hline Mini wind & $7 \mathrm{~kW}<\mathrm{P}_{\text {rated }}<50 \mathrm{~kW}$ & $\mathrm{~A}<200 \mathrm{~m}^{2}$ \\
\hline Small wind & $50 \mathrm{~kW}<\mathrm{P}_{\text {rated }}<100 \mathrm{~kW}$ & $\mathrm{~A}<300 \mathrm{~m}^{2}$ \\
\hline
\end{tabular}


Also there are categories for wind turbines based on different criteria such as:

i. $\quad$ Drag and lift-based VAWTs.

ii. Upwind and downwind SWTs.

iii. Geared and direct-drive SWTs.

iv. Stall and pitch controlled SWTs.

v. Off-grid, on grid, and hybrid SWTs.

vi. Off shore and on shore LWTs [3, 4].

The advantages of SWTs are:

Can be used in urban and semi-urban areas.

Can be used as telecommunications towers.

They are preferred for remote houses.

Towers are easy to install (compared to LWTs), no cranes or heavy machinery needed.

They are durable in hard conditions weather such as storms and rain.

$>$ They occupy less space than LWTs and could be placed near any property.

$>$ They can be used for on- or off-grid applications.

$>$ They have a lower level of noise compared to LWTs.

The wind turbines can be also categorized according to the number of blades for the rotor. Thus, this number varies from one to multiple blades changing some parameters in wind turbine performance. In general, the wind blows in different velocities, so the stresses on blades become massive and fluctuating. The blades will be under changing amount of aerodynamic torque as a result of constant blowing of wind from multi directions. Theoretically, the maximum power coefficient for any wind turbine is related to Tip Speed Ratio (TSR), the ratio between Blade Tip Speed (vtip) to undistributed wind speed (v0) or the ratio between the wind speed restricted flow over the blade and the speed flowing freely without restriction. The losses for an aerofoil wind turbine blade (drag and tip losses) are connected to the total number of blades of a rotor and thus reduces the power coefficient. The maximum reachable power coefficient for turbines with the optimum blade profile with finite number of blades and aerodynamic drag has been calculated by Wilson et al. in 1976 as shown in Figure (5) [3, 4]. 


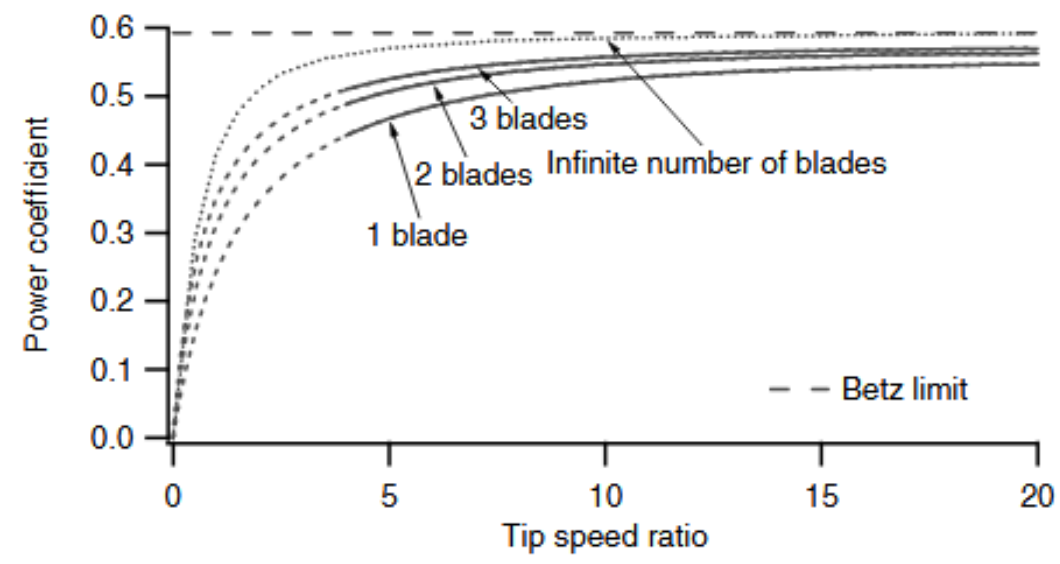

Figure (5). Power coefficients with number of blades (drag neglected).

The deviation of the data within $0.5 \%$ with the range of tip speed ratios from 4 to 20 , lift to drag ratios $(\mathrm{Cl} / \mathrm{Cd})$ from 25 to infinity. The single to triple blade (B) is described by the following equation [5]:

$$
\mathrm{C}_{\mathrm{p}, \max }=(16 / 27) \lambda\left[\lambda+\left(1.32+(\lambda-8 / 20)^{2}\right) / \mathrm{B}^{2 / 3}\right]^{-1}-\left[(0.57) \lambda^{2} / \mathrm{Cl} / \mathrm{Cd}(\lambda+1 / 2 \mathrm{~B})\right]
$$

where: $\lambda$ is the tip speed ratio (TSR).

Based on Eq. (1), the maximum reachable power coefficients for 1, 2, or 3 blades with the assumption of zero drag are shown in Figure (5). The figure also shows the condition of infinite number of blades (the case of a wake rotation). As a conclusion, and for a constant tip speed ratio, when we use a fewer number of blades, we get lower possible $\mathrm{Cp}$. In general, the majority of wind turbines run with 2 or 3 blades, and the TSR for the two bladed wind turbines are higher than the three blades wind turbines. Thus, the practical reachable Cp between typical $2 \& 3-$ bladed wind turbines is almost the same assuming drag is neglected. For a three bladed turbine, we can see the effect of lift to drag ratio $(\mathrm{Cl} / \mathrm{Cd})$ on maximum reachable power coefficient in Figure $(6)[4,5]$.

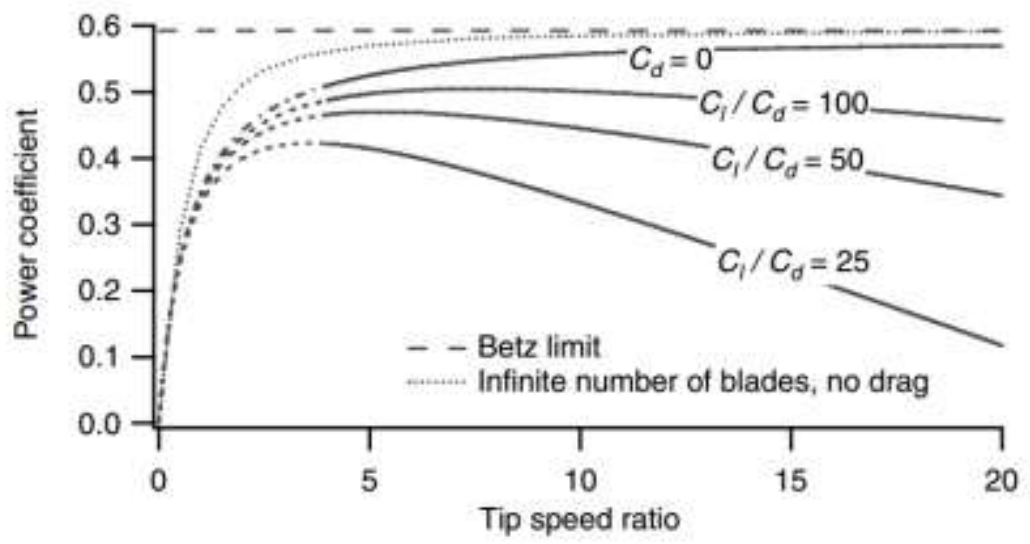

Figure (6). Maximum power coefficient for 3-bladed turbine related to coefficient of lift to drag ratio [5].

From Figure (6), we can see the reduction of maximum reachable power as the forces of drag on the blades increase. As a result, the designer should use blades or airfoils with high lift to drag ratios $[4,5]$.

Mechanical power of a turbine, is a portion of the total power of the wind. By converting the kinetic energy of the blowing wind into a mechanical energy, the turbine rotor affects the wind, causing the streaming air to be slowed down, i.e., the air velocity on the downwind side of a turbine is much slower than the upwind side. In natural circumstances, the air starts to slow down before it hits the rotor blades, so the velocity is reduced through the 
imaginary cylinder or disc created by the rotor blade tips. The area of that imaginary disc is called swept area (A). Accordingly, there will be a value of a maximum mechanical power that can be harnessed from air within a certain disc area (swept area). An ideal turbine would reduce the velocity of air by $2 / 3$ of its original value. The maximum value is 59\%, which is called the "Betz's limit" [6]. In the commercial turbines, only 40-50\% can be reached so far $[6,7]$. The mechanical power $(\mathrm{Pm})$ extracted from an air velocity at the rotor $(\mathrm{v})$ is $[6,7]$ :

$$
P_{m}=C_{p} 0.5 \rho \mathrm{Av}^{3}
$$

where: $\mathrm{Cp}$ is a suitable coefficient of performance, $\rho$ is the air density $(1.23 \mathrm{~kg} / \mathrm{m} 3)$ at a normal atmospheric pressure, and $\mathrm{A}$ is the swept area.

Another factor to define power of wind turbines is solidity $(\sigma)$. Solidity is the percentage of the circumference of the rotor, which contains material rather than air [8].

$$
\boldsymbol{\sigma}=\mathbf{N} \times \mathbf{A} / \boldsymbol{\pi} \mathbf{R}^{2}
$$

where: $\mathrm{N}$ is the number of blades, and $\mathrm{R}$ is wind turbine radius. The effect of solidity on the generated power is shown in Figure (7). According to this diagram, any increase in solidity (i.e. number of blades) means an increase in generated power and power coefficient.

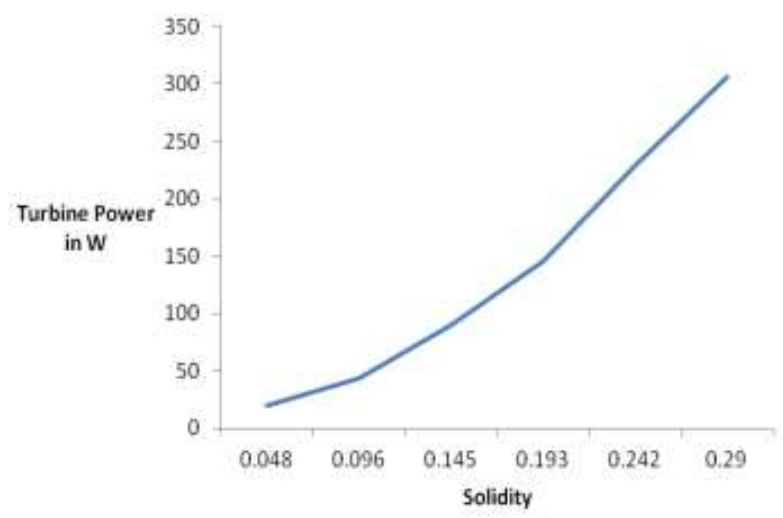

(a)

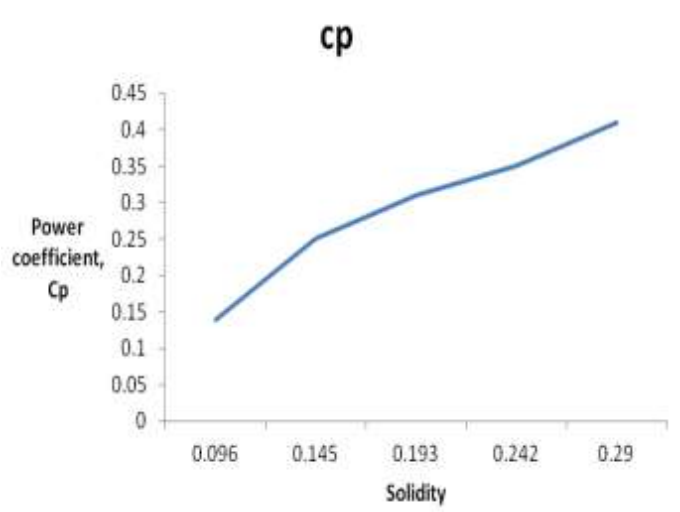

(b)

Figure (7). (a) solidity vs. power harnessed by wind turbine, and (b) solidity vs. power coefficient [9].

Small horizontal wind turbine is defined under the table of SWT classification as Pico type. This type of turbines with a capacity of less than $1 \mathrm{~kW}$ is useful in rural areas and remote houses and could be used for emergency and electronic systems in schools and clinics. Moreover, the cost of these turbines is low and their performance is considerably high comparing to other larger turbines.

This paper aims to investigate a Pico-type horizontal wind turbine for tutoring purposes using a small DC generator. The prototype will be used as an exhibition model in our lab (REERC lab). The effect of the number of blades on the performance of this turbine is also investigated. The results have been also compared with the literature to draw a conclusion on the performance of a Pico wind turbine compared to the commercially scaled wind turbines.

\section{Experimental Procedure}

An air blower producing air speed on the tip around $47 \mathrm{~m} / \mathrm{s}$ was used in this study. To obtain different air speeds along the streamline, a bench in which the experimental procedure carried out was lined up at various distances from the blower and wind speed was recorded at each distance by using anemometer (Type EXTECH). A small DC motorized fan with a nominal power of $4 \mathrm{~W}$ was used to simulate a Pico wind turbine. The speeds were taken from the tip (Distance $=0$ ) until the blades stop rotating, with each step the air speed, current, and voltage, were recorded. Figure (8) is a photograph of the experimental setup. 


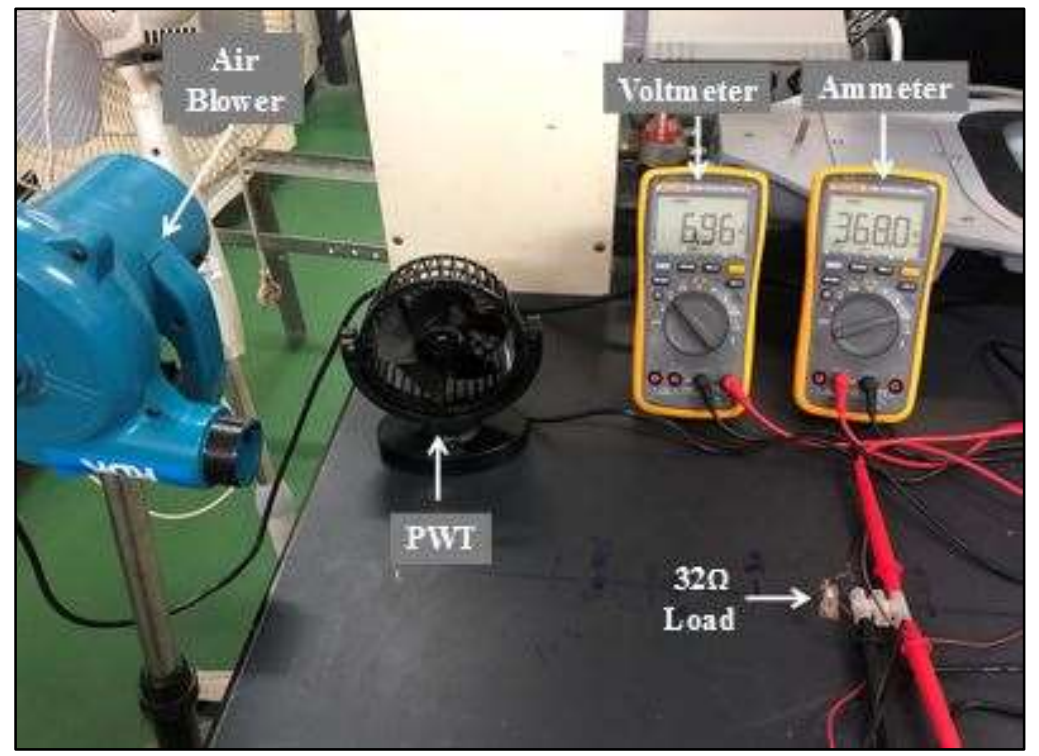

Figure (8). A photograph of the experiment setup used in this work.

Prior to the measurements, a load resistance was chosen to be as same as the internal resistance of the wind turbine coil to extract a maximum power point (MPP) from the turbine. To achieve that, a default resistor with known load was first used to calculate the internal resistance as follows:

$$
\begin{aligned}
& V_{G}=V_{T}+V_{I} \\
& V_{G}=I \cdot R+I . r \\
& V_{G}=I(R+r) \\
& r=\frac{V_{G}}{I}-R
\end{aligned}
$$

where: $\mathrm{r}$ is the internal resistance, $\mathrm{R}$ is a known resistor, $\mathrm{I}$ is the current passing through the series circuit, VG is the generated voltage (open circuit voltage), VT is the terminal voltage (voltage across the resistor), and VI is the drop voltage due to the internal resistance. According to the above calculations, the load resistor was calculated to be $32 \Omega$ after measuring the parameters in Eq. (7).

PWT of 5 blades, 2 blades, and 1 blade fans were used by starting with the 5 blades all the way to 1 blade by cutting off the blades to the desired number. Figure (9) shows the blades used in this work. The cp values in this work are considered to be as $0.3,0.35$, and 0.4 for 1,2 , and 5-bladed turbines, respectively. These values are approximate based on the literature [9] as discussed earlier.

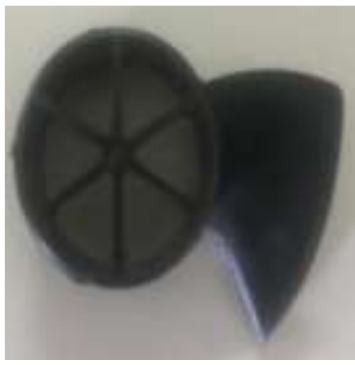

1 blade

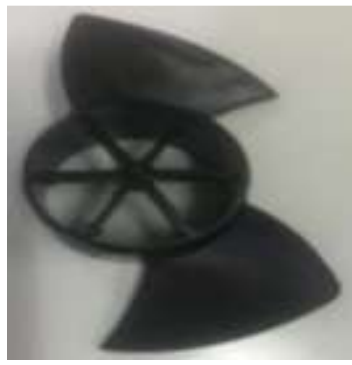

2 blades

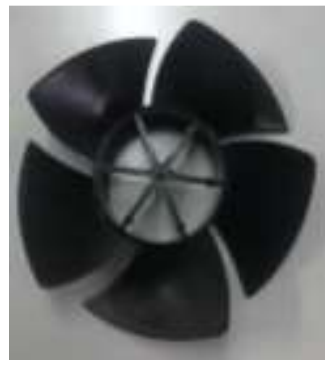

5 blades

Figure (9). 1, 2, and 5 blades fans used in this work. 
The cut-in speed was recorded at the wind speed in which electrical power was generated. At this speed, the generation is surpassing the internal loss due to the internal resistance. Rated speed was also determined when maximum power was reached, whereas cut-out speed was determined at the point of power dropping to nearly zero. Several wind speeds were set between cut-in and cut-out speeds by adjusting the distance between the blower and the turbine.

\section{Results and Discussion}

Figure (10) illustrates the mechanical wind power extracted from the wind simulator used in this experiment with a cp proposed to be 0.4 for a 5-bladed wind turbine. The maximum obtained air speed is $46.3 \mathrm{~m} / \mathrm{s}$ at blower tip giving us the maximum mechanical power of $138.6 \mathrm{~W}$ and the minimum value of $0.133 \mathrm{~W}$ with the corresponding average air speed of $4.56 \mathrm{~m} / \mathrm{s}$. The diagram of Figure (9) gives a homogenous parabolic cubic growth that matches the elements of the power formula as in Eq. (2) shown earlier. This plot gives the theoretical power behavior of moving air under steady conditions of air speed.

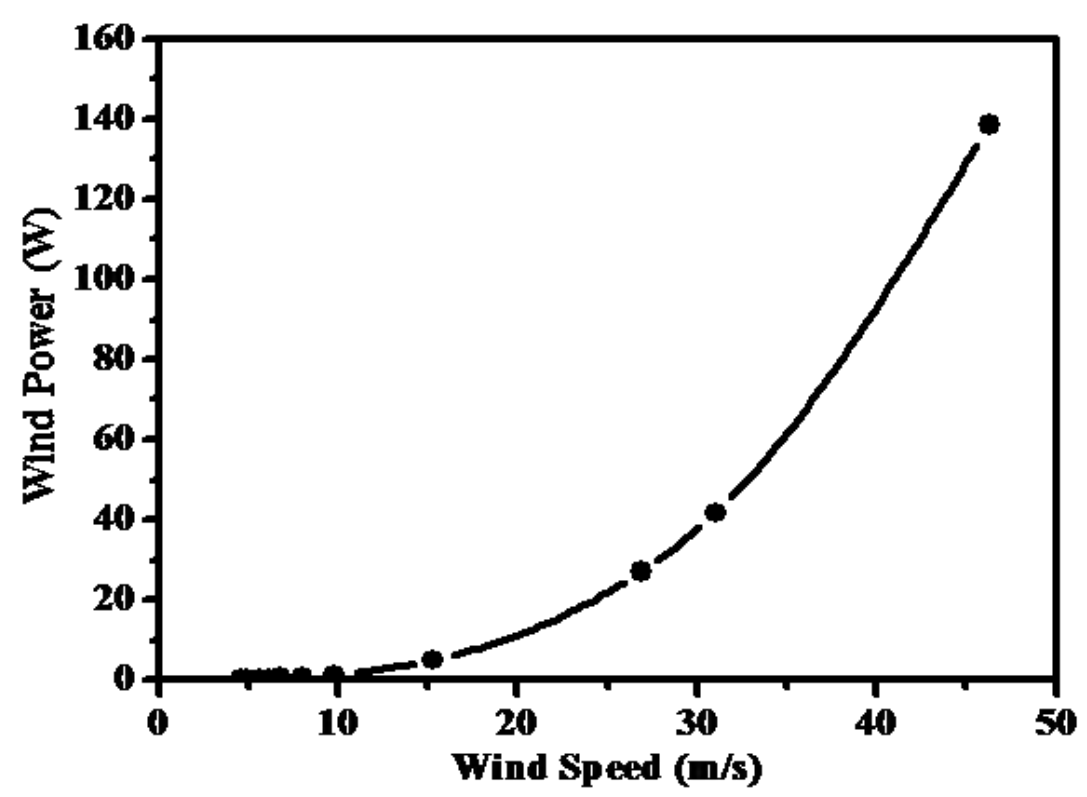

Figure (10). Five-bladed mechanical power curve $(\mathrm{cp}=0.4)$.

Figure (11) illustrates the electrical output power of the 5-bladed Pico wind turbine used in this work. The figure exhibits a typical behavior with a cut-in, cut-out, and rated speeds, where highest electrical power obtained for this case was $2.6 \mathrm{~W}$ at a rated speed of $31 \mathrm{~m} / \mathrm{s}$. The behavior of this curve matches the ideal HAWT behavior very well [10]. The cut-in speed of this turbine is $4.9 \mathrm{~m} / \mathrm{s}$, while the start-up speed (the speed when the turbine hub starts to rotate with no electrical power detected) is $4.56 \mathrm{~m} / \mathrm{s}$. The difference between start-up and cut-in speeds $(0.34 \mathrm{~m} / \mathrm{s})$ corresponds to the power loss inside the turbine, includes Joule losses in the wires of the coil and friction losses in the sleeve bearing. At air speed of $4.9 \mathrm{~m} / \mathrm{s}$, the generated power surpasses the internal power losses and the net power is what we can detect and measure. 


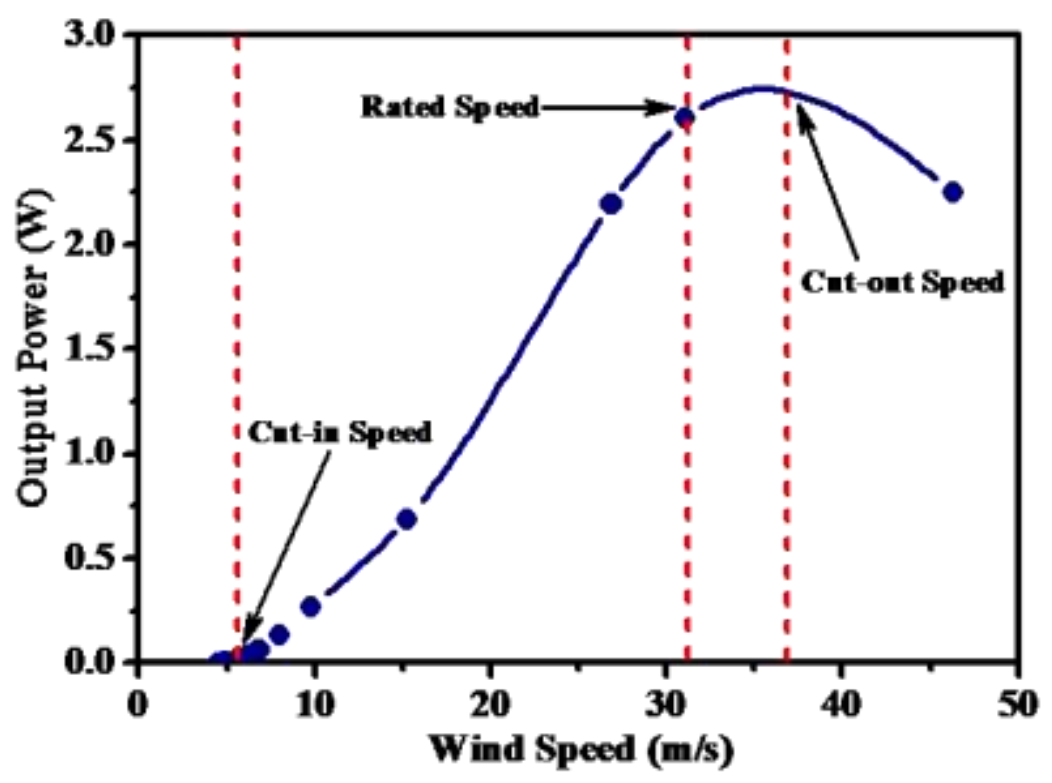

Figure (11). Five-bladed output electrical power curve.

The 5, 2, and 1-bladed Pico wind turbine output powers alongside the wind input power are presented in Figures $(12,13 \& 14)$. We can see a noticeable reduction in power generated due to the reduction of blades in addition to power generated due to reduction in speeds. For the 5-bladed turbine, the cut-in speed starts at $4.9 \mathrm{~m} / \mathrm{s}$, whereas with 2-bladed turbine, the cut-in speed occurs at $8 \mathrm{~m} / \mathrm{s}$, and with 1-bladed turbine, the cut-in speed rises to $19.15 \mathrm{~m} / \mathrm{s}$. This increment in starting speed is due to several reasons, including dynamic structure and balancing problems due to polar asymmetrical rotor [11]. On the other hand, the decrease in electrical power with reducing blades number can be explained by the decrease in solidity as explained elsewhere (see Figure 7).

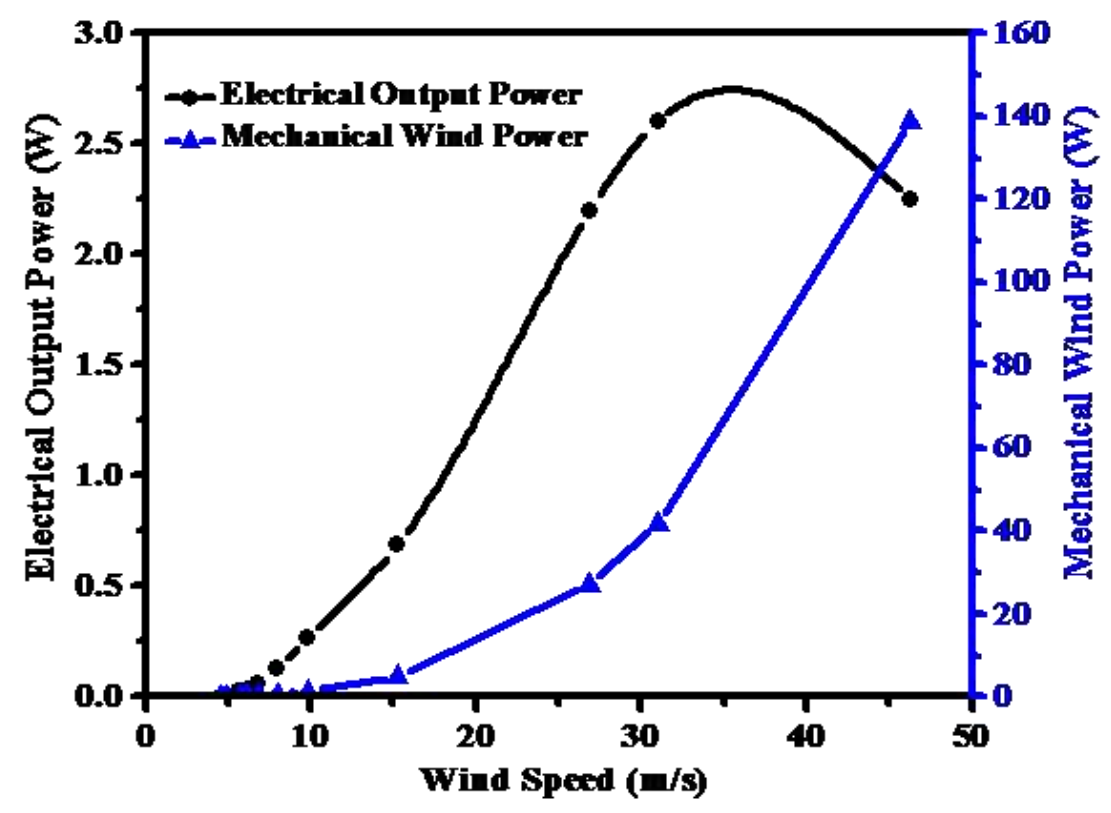

Figure (12). Five-bladed power curve (Mechanical \& Electrical). 


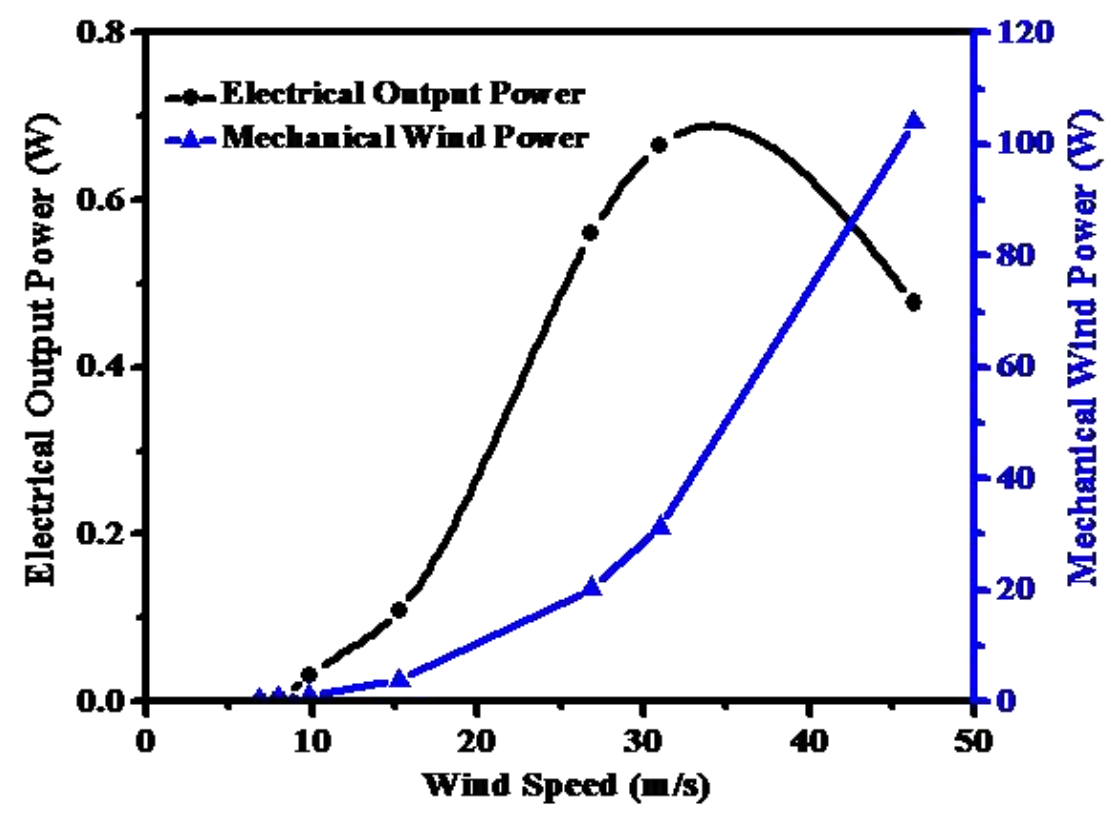

Figure (13). Two-bladed power curve (Mechanical \& Electrical).

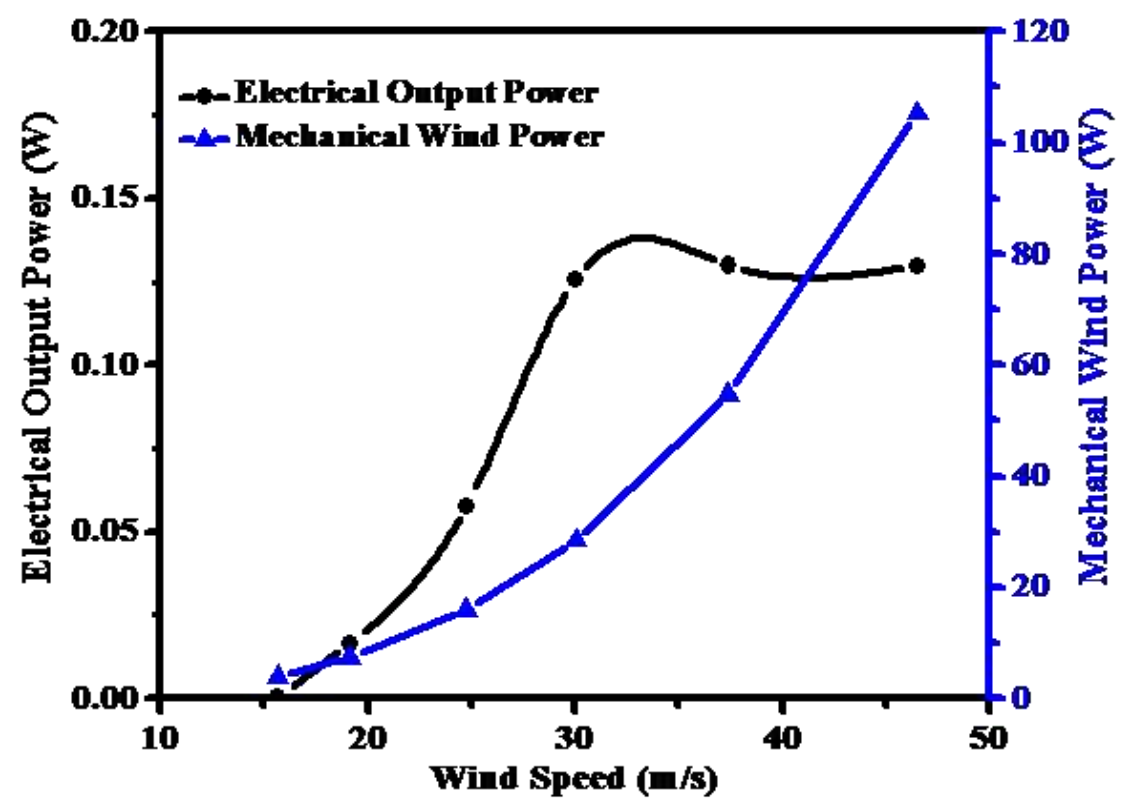

Figure (14). One-bladed power curve (Mechanical \& Electrical).

\section{Conclusions}

The reduction in number of blades shows a noticeable reduction in generated power and power coefficient. From scientific prospect, sharp reduction of the solidity factor affects the generated power. In addition, operational flaw due to imbalance problems during rotation can be another factor for the power reduction in the 1-bladed and in 2bladed fans. To surpass such problem, the design of blades must change including airfoil and angle of attack (to enhance the relatively high cut-in speed) for the blades. Moreover, a distribution of weights along the rotation axis has to be considered.

Acknowledgement: Financial and logistic support from the Renewable Energy and Environment Research Center (REERC) at the Corporation of Research and Industrial Development is greatly recognized and appreciated. 


\section{References}

[1] J. K. Kaldellis, D. Zafirakis, "The wind energy (r)evolution," Renewable Energy, vol. 36, pp. 1887-1901, 2011. [2] P. D. Fleming, S. D. Probert, "The evolution of wind turbines: an historical review," Appl. Energy, vol. 18, pp. 163-77, 1984.

[3] J. Earnest, Wind Power Technology. Delhi-110092: PHI Learning Private Limited, 2011, pp.394-435.

[4] T. Burton, et al., Wind Energy Handbook. Chichester, England: John Wiley \& Sons, Ltd, 2011.

[5] J. F. Manwell, et al., Wind Energy Explained Theory Design and Application. Chichester, England: John Wiley \& Sons, Ltd, 2009.

[6] A. V. DaRosa, Fundamentals of Renewable Energy processes. Oxford, England: Elsevier, 2013.

[7] M. O. Hansen, Aerodynamics of Wind Turbines. London, England: James \& James Ltd, 2000.

[8] P. J. Schubel, et al., "Wind Turbine Blade Design," Energies, vol. 5, pp. 3425-3449, 2012.

[9] R. Kumar, et al., "Solidity Study and its Effects on the Performance of A Small Scale Horizontal Axis Wind Turbine," Energy Centre, Maulana Azad National Institute of Technology, 2017.

[10] E. Hosseini \& G. Shahgholian, "Output Power Levelling for DFIG Wind Turbine System Using Intelligent Pitch Angle Control," Journal for Control, Measurement, Electronics, Computing and Communications, vol.58, no. 4, pp 363-374, 2018.

[11] S. Eriksson, H. Bernhoff, M. Leijon, "Evaluation of different turbine concepts for wind power," Renewable and Sustainable Energy Reviews, vol. 12, Issue 5, pp 1419-1434, June 2008. 